\title{
Operational research(ers) in development: Growing a new generation of operational researchers
}

\author{
I Durbach* \\ $\mathrm{L} \operatorname{Scott}^{\dagger}$ \\ J Nyirenda ${ }^{\dagger}$ \\ S Silal $^{\dagger}$ \\ Received: 29 June 2012; Revised: 1 February 2013; Accepted: 8 February 2013
}

\section{Dedication to Emeritus Professor Theodor Stewart}

To Theo, for his enormous, enduring (and continuing!) contribution to the theory and practice of operational research at the University of Cape Town.

\begin{abstract}
This paper explores the theme of training operational research (OR) practitioners in South Africa by critically evaluating a Masters program in Operational Research in Development (ORD), launched in 2005 at the University of Cape Town. This program was specifically focused on applying OR to the problems of the developing world in general and Africa in particular. We describe the program and review the practical work undertaken by students participating in the program. Topics range widely across domains including health (antimalarial drug resistance); poverty (food banking); governance (NGO management structures and monitoring of local government performance) and sustainable livelihoods (spaza shop operations). We use the review to highlight strengths and weaknesses of the program, as well as challenges faced in the OR education in South Africa at a postgraduate level.
\end{abstract}

Key words: $\quad$ OR in development, philosophy of OR, practice of OR, problem structuring methods.

\section{Introduction}

This paper is concerned with operational research (OR) education in South Africa, and specifically with the training of OR practitioners who possess the skills needed to address the challenges of a developing country. We critically evaluate a Masters program in Operational Research in Development (ORD), launched in 2005 at the University of Cape Town (UCT) by Professor Theo Stewart, with assistance from Professor Arabinda Tripathy of (at that time) the Indian Institute of Technology in Kharagpur, and review a number of dissertations undertaken by students on this program. We use this review to reflect on challenges facing postgraduate education in OR in South Africa.

The issue of OR education in any country is intimately related to the social, economic, and political climate of that country, since these to a large extent define what skills will

\footnotetext{
${ }^{*}$ Corresponding author: Department of Statistical Sciences, University of Cape Town, Rondebosch, 7701, South Africa, email: ian.durbach@uct.ac.za

${ }^{\dagger}$ Department of Statistical Sciences, University of Cape Town, Rondebosch, 7701, South Africa.
} 
be demanded of a graduating student. In South Africa, which is defined by the World Bank as a "developing" country (World Bank 2012), this means that OR education cannot be meaningfully discussed without some reference to "development" and specifically OR in development. The role of OR in developing countries has been discussed at length in both developed and developing countries (White 2011). We do not attempt to give a comprehensive review of ORD here, although there is some inevitable overlap in the issues we consider.

The postgraduate ORD program at UCT was specifically designed to be highly applied, with an overarching aim of preparing graduates for a career in applying OR to the problems of the developing world in general and Africa in particular. This, to the best of our knowledge, made the program unique in Southern Africa and in our view differentiated it from many OR programs in both the developed and developing world, making an assessment of its successes and failures of broader interest.

The remainder of the paper is structured as follows. The next section gives a review of OR in development, with the aim of putting the MSc ORD program in its proper perspective rather than providing a complete review of the field. The details of the ORD program are discussed in $\S 3$. In $\S 4$ the practical projects undertaken by the students in the program as part of their dissertations are reviewed. Some personal reflections on the program, highlighting the challenges faced as well as perceived strengths and weaknesses are provided in $\S 5$. Finally $\S 6$ concludes the paper.

\section{Literature review}

This review comprises two subsections. The first explores the concept of development, while the second supplies a brief background on OR in development.

\subsection{What is development?}

Addressing the topic of ORD requires some clarity on what is meant by development. This is a lengthy and often controversial debate (Willis 2005), which we will not enter into in any detail here (Willis 2005). It is clear that there are some countries that are on average worse off materially than others. Historically, international organizations like the World Bank have preferred a dichotomous categorisation of countries. The label used to identify undeveloped countries is controversial and relatively fluid - the terms underdeveloped, less developed, least economically developed, third world have all been used at some point (White 2009). We use the label of developing currently used by the World Bank, which includes all countries with a Gross National Income per capita below $\$ 12475$ (World Bank 2012).

What constitutes development in developing countries is also highly controversial, as are the best ways to achieve this development (Rapley 1996; Willis 2005). The main debates here revolve around whether or not development is a linear, deterministic process; and the role of developed nations in assisting or stunting this development. Again, we shall not enter into these debates. While noting the difficulties involved, documents like the Millennium Development Goals provide much insight into the kinds of practical problems 
that are generally accepted as fostering development: eradicating poverty and hunger; achieving universal primary education; reducing child mortality; combatting HIV/AIDS, malaria, and other diseases, etc. Many of these are instantly recognizable as challenges facing South Africa.

\subsection{Operational research in development (ORD)}

The role played by OR in developing countries, specifically in addressing problems of development, has received much attention from operational researchers and their governing structures. The International Federation of Operational Research Societies (IFORS) has for some 40 years advocated the use of OR in developing countries (White 2009), most notably through high-profile prizes for applications of OR to development (see http://ifors.org/web/ifors-prize-for-or-in-development/) and the establishment and organization of regular ICORD (International Conference on OR for Development) conferences dedicated to ORD (Rand 2004). In addition EURO (the Association of European Operational Research Societies) also has an active working group working on ORD (http: //www . euro-online.org/web/ewg/29/or-for-development-ewg-ord). Regional groupings in or across developing countries - for example, the Operational Research Practice in Africa group (ORPA http://www orpagroup.net/), and national OR societies like the Operations Research Society of South Africa (ORSSA http://www.orssa.org.za/) or India (ORSI http://www.orsi.in/) - also have regular development initiatives.

The intersection of OR and broader research on development is primarily concerned with two main themes (White, 2009). The first is how OR is practiced in developing countries, a categorisation which includes how OR is conceived or thought of (e.g. Aggarwal, 1994); how OR is taught (Walsham 1978; Yousef 2009); and specific OR case studies (e.g. Neiva de Figueiredo 2012; Haouari 2011). Fatti (1988) and Stewart (1995) have reviewed the history, practice and organisation of OR in South Africa. The case studies in particular can either be "regular" OR problems that just happen to take place in developing countries (e.g. Rossouw et al. 2010), or can be developmental problems (e.g. Scott 2005). In both cases, these applications can be used to draw out features which frequently (but not always) characterise OR practice in developing countries. These include the following:

- It takes place in contexts that are lacking in resources and as a consequence are data poor.

- There is a strong imperative for methods to be participative (Rosenhead and Tripathy 1996), either because a paucity of data leads to a need to work closely with stakeholders to unravel the problem (Stewart 2006) or due to negative experiences in receiving aid and technological support in the past (Chambers 1994). The latter problem may extend to all situations (i.e. both developed and developing) where the sponsor is not the client, but is perhaps more keenly experienced in the developing world.

- Solutions that rely on high levels of technology/expertise will often not be fully implemented, either because some sector of participants who are key to success will have low levels of literacy/numeracy, or because there are insufficient resources to sustain high-tech solutions (Zachariah 2012). 
- It is likely that government will be both part of the problem and part of the solution (White, 2011). This underscores the need for methods to be transparent and to be a record of decision making with respect to the use of public or donor funds. It also underscores that the socio-political context may constrain available solutions or approaches (White 2011).

The second theme is the ability of OR to help countries achieve development, including the extent to which OR applications in developing countries overlap with development goals and whether OR methods are appropriate to the problems faced in developing countries (Rosenhead 1993). The latter includes both regular OR problems that happen to be conducted in a developing country and development problems. With respect to the second of these subthemes, which is more relevant to the current paper, we note the following:

1. The fact that there is, on the one hand, a paucity of resources and, on the other, a diverse set of stakeholders and participants, implies that, to some extent at least, there will need to be new or innovative approaches developed to situations which are uncovered out of need and which demand urgent attention. Rosenhead (1993) cites a number of cases that speak to this issue. This means that the modus operandi of ORD is frequently that of action research, i.e. there is a recognition of the pressing need for solutions but at the same time there is a commitment by the researchers to ensure proposed interventions are informed and underpinned by relevant and rigorous theory. Moreover there is a commitment to further develop and advance the theoretical basis of the intervention, in an attempt to make the research work generalizable and broadly useful. Ideally, this synergy (or tension between urgency of need and rigour of approach) could lead in many cases to on-going relationships between academic/research institutions and government/NPOs/NGOs.

2. The lack of resources makes it likely that there has been little in the way of planning, visioning or problematizing. At the same time the fact that there is often a wide diversity of stakeholders and interested and affected parties, sometimes spanning different language and culture groups, makes these initial stages of any intervention, where boundaries, roles and expectations are defined, crucial to overall success. The urgency of need is likely to make participants keen to skip preliminary problem structuring phases, something ORD practitioners need to be aware of but not overwhelmed by (Scott 2005a).

3. Good OR requires a good understanding of the target organisation's culture and objectives (Fildes 1997). This understanding takes time to develop and the culture of the organisation itself may dictate the pace of this happening.

\section{Overview of the ORD program at UCT}

The ORD program is a Masters (MSc) degree program offered by the Department of Statistical Sciences at UCT, which houses operational research/management science as well as statistics. The curriculum ${ }^{1}$ consists of coursework and a half-dissertation (normally on an applied OR topic). The coursework extends over nine months from February to

\footnotetext{
${ }^{1}$ For further details, see http://web.uct.ac.za/depts/stats/documents/MScORDinfo.pdf.
} 
November of the first year of registration. This is followed by the dissertation, which would typically take around six months.

The program has a strong applied component, and aims to prepare graduates for a career in applying OR to the problems of the developing world. The entry requirements into the program stipulate that applicants must possess a good honours degree (usually exceeding a $65 \%$ average) which includes a strong quantitative component (normally at least two years of mathematics at a tertiary level).

Students select from a suite of core and elective modules to build up a coursework load of 22 credits. The core required material during the coursework phase consists of modules:

- OR in development (6 credits): A detailed module on the history and nature of OR and ORD with an exploration of a variety of case studies on the application of OR and ORD in both the developed and developing world.

- OR methods (4 credits): An extensive overview of traditional quantitative OR techniques including mathematical programming methods, Dynamic Programming, Queuing theory and Simulation.

- Project management (4 credits): An exploration of Critical Path Analysis and Program Evaluation and Review Technique (PERT) with practical applications.

- Problem Structuring methods (2 credits): A focus on the background theory and concepts underlying Problem Structuring, including extensive coverage of specific methods such as Soft Systems Methodology, Cognitive Mapping Approaches, Strategic Choice and Robustness Analysis.

- System Dynamics (2 credits): An introduction to Systems Thinking and the modeling process, understanding the structure and behaviour of dynamic systems and the mathematical under-pinnings of dynamics of growth.

The remaining 4 credits are chosen from a set of elective courses that may change from year to year but typically include: Analysis of Survey Data, Econometrics, Time Series Analysis, Spatial Statistics, Demography and Development Economics. Following the course work, students embark on a dissertation in which they are encouraged to pursue applied OR projects rather than more theoretical research. This dissertation is not as onerous as a masters degree by dissertation only, but will still typically require between three and six months of dedicated full-time work. In the following section, we review a selection of these dissertations.

\section{Case studies: Addressing real issues of development na- tionally, regionally and locally}

In the half-dissertation component of the program, students are encouraged to tackle real developmental issues in real contexts. A review of the topics undertaken over the years in which this program has been offered reveals an array of weighty issues of national significance, focussed on local or regional level outcomes and interventions. The topics range widely across domains including health, poverty, governance, and sustainable livelihoods. 


\subsection{An application of problem structuring methods to the spaza shop system in South Africa}

Spaza shops are small informal businesses that operate by selling basic grocery items from a section of an occupied residential home, often in a disadvantaged community (Ligthelm 2002). The spaza shop system is a value chain that links low-income township consumers to manufacturers, wholesalers, distributors, and other suppliers of products and services. Although a large and important component of South Africa's economy, relatively little is known about how the system operates or what forms an improvement to the system might take (e.g. Ligthelm 2002; Ligthelm 2005; Perks 2010). In OR terms, the spaza shop problem is not well-structured. Furthermore data is typically unavailable or of poor quality, because many spaza owners operate sporadically and do not maintain records. This dissertation (Sabwa 2009) used two problem structuring methods to gain a better understanding of the system and identify potential improvements. The analysis was performed for a South African NPO acting as a market development facilitator - designing and managing projects enabling poor communities to meaningfully participate in markets.

The organisation's stated aim for the dissertation was to identify and overcome constraints in the spaza market in Cape Town in the supply and distribution of goods from manufacturers, wholesalers and distributors to spaza shops. The dissertation employed a combination of causal mapping (Scavarda et al. 2006) and root definition building (Checkland 1998; 2000) to structure the problem. Causal mapping is a visual tool used to graphically represent the thoughts of an individual or group regarding a specific issue, in this case the spaza shop system. The resulting diagrams are visual aids depicting how inter-related variables interact with each other, employing a set of nodes connected by loops as a notational device. A root definition is a structured description of the purpose for which a system exists, as seen from a particular point of view, usually formalised using the so-called "CATWOE" mnemonic: customers (people who would be the victims or beneficiaries of the purposeful activity); actors ( people who would do the activities); transformation process (the purposeful activity changing inputs into some expected outputs); worldview (a point of view that justifies the existence of the system); owner (people who would have the power to initiate or stop an activity); and environmental constraints (constraints from the immediate environment that should be taken as given). The formulation of root definitions was based on four possible perspectives of the spaza shop system, developed as part of the dissertation, viz: they provide an essential service for township consumers to purchase basic grocery items; they provide a source of income for those with few other opportunities; they service a large and relatively untapped market; and they uplift communities.

The dissertation's primary output, as summarized in the causal map and root definitions, was a systems view of spaza shops that may be of use to researchers and policy-makers working in the field. The focus in the recommendations is on solutions related to endogenous factors facing spaza shop owners, because these tend to be manageable at the spaza shop level and were identified as key by the stakeholder. Three main areas were identified: improving management skills, improving the networks between spaza shops and partners, and helping spaza shops to raise their sales volumes. Subsequently, a simple spreadsheetbased decision support tool was designed to help spaza shop owners understand inventory management and decide on a suitable ordering strategy for the products which they carry. 
This dissertation was faced with a problem common to many of the student projects that attempt to work with a diverse group of stakeholders, namely a progressive decline in stakeholder participation during the process. The net result for this dissertation was that the problem structuring was based only on initial interviews, with no meaningful interaction or feedback obtained on the results of the model-building process. It is thus not known to what extent the problem structuring results and associated decision support are useful or have been used. The reasons for this decline were not clear, but on reflection it is possible that the stakeholders were expecting to progress quickly through problem structuring into a technical analysis that provided optimal solutions to known problem areas like stock shortages, stock losses, and transport costs. This highlights an aspect that was particularly demanding on students of the program: given the pressing needs borne out of high levels of poverty and inequality and difficulties in communicating subtle ideas across multiple language groups, unrealistic ideas about delivery and in particular, speed of delivery (of project outcomes) need to be managed from the start of the project. It may have been advantageous to spend more time early in the process (a) stressing that only some problem areas were known a priori, and the value of problem structuring in drawing out those that were less clear; (b) combating the belief that problem structuring is just an inconvenience on the path to solving the real problems that should be cleared as quickly as possible; and (c) managing expectations of the process, since the available data was always going to be too poor to reliably answer questions of operational efficiency.

\subsection{A simulation model of antimalarial drug resistance}

This dissertation (Silal 2009) focused on building a mathematical model of transmission and the spread of resistance to Sulfadoxine/Pyrimethamine (SP) in Mozambique where both SP and SP in artemisinin-based combination therapy (ACT) are the first-line therapies for malaria. The model was developed using differential equations, a technique that allowed for the modeling of stocks and flows that represent different stages in the disease process and the rate of movement between these stages respectively. The transmission model had the basic structure of a Susceptible-Exposed-Infectious-Recovered (SEIR) disease model with further stratification for drug type and degree of resistance to SP (Anderson \& May 1980). The model was simulated for a population of 1000 people for 11 years from starting conditions similar to that in 1999. Two policy interventions were tested on the model once the model reached a steady state: indoor residual spraying and a new drug regime $(\mathrm{ACT})$. The model showed that introducing these two antimalarial interventions decreased prevalence by $70 \%$ in the 11 year period. The model postulates that while ACT had a dramatic effect in reducing prevalence of malaria, it also appears to have changed the resistance profile of remaining infections in that there were proportionately more resistant infections in the population. Data required to drive the model was either not available or of a poor quality in many cases and the student was forced to generate input data by performing a literature review and meta-data analysis on published statistics to define the flows that drive the differential equation model.

The focus of the student in this dissertation was largely on the essentially quantitative technique of differential equation modelling. However, in order to extend the usefulness of this model to a less-numerate or technically minded stakeholder group and to policy- 
makers who may not have the levels of numeracy required to fully interpret the results of this model, it was framed as part of a greater systems analysis problem. A causal map was developed to provide a view of all variable interactions and behaviour relevant to the malaria system. The diagram depicts the impact that factors such as policy interventions, market dynamics, policy implementation and other environmental aspects have on malaria transmission, and is potentially of use to policy/decision-makers in assessing the overall impact of changes in the malaria system.

\subsection{The use of problem structuring methods to explore the functioning and management of a selected NGO}

This dissertation (Anyogu 2012) aimed to explore issues around the management structure of Students Health and Welfare Centres Organisation (SHAWCO), an organisation constituted in the 1940s to provide free social and medical services to needy communities through voluntary participation of UCT students. The study attempted to highlight problems encountered as a result of so-called management inefficiency.

As is common with poorly-structured or so-called messy problems, there was a strong sense that something was wrong and a nebulous desire for change, but without any clear consensus on how best to achieve this. The student conducted a number of individual interviews amongst staff members and clients (end users of SHAWCO services) and culminated with a joint workshop of all SHAWCO staff. The aim of this process was to foster a sense of shared understanding of the organisation, its structure, processes and component parts, with a view to identifying better ways of doing things. These interview and workshop processes were guided by an approach called SODA (Eden \& Ackerman 2001), a problem structuring method based on personal construct theory (Kelly 1955), a theory of personality. SODA holds that reality is made up of the different ways in which interested and affected parties of a system view it. Personal construct theory is of the opinion that individuals construct views of reality in a positivist way, so as to make sense of the world around them, ultimately to solve problems. This sense-making often involves postulating contrasts (what one does want as opposed to what one does not) and specifying the causal relations between the constructs that lead to a particular situation. SODA is a process of working with individual stakeholders to capture their individual cognitive maps (series of causally linked constructs) and then working with the group of stakeholders to create a consensus merged map, which incorporates all individual views.

A number of valuable insights were raised during the problem structuring process. One of the unique contexts for SHAWCO is that although there is a core of management that is permanently employed, there is a significant (student) component that is voluntary and transitory. This impacts on institutional memory and makes the organisation somewhat slow to respond to pressure for change. There were also schisms in the organisation due to perceptions of some people being "in the know" and others not. This context makes it imperative for processes to be participative. Another important aspect is a strong sense of partnership with government agencies (namely the departments of Health, Education and Social Services) which further hampers the organisations ability to be responsive: it is tied to external systems and policies which may themselves be perceived to need to change. There was an overriding imperative for transparency and accountability because of the 
use of donor funds, compounded by the fact that the organisation is attached to UCT which has some oversight role. The historical and political context of SHAWCO and how the organisation is perceived by its clients was of key importance and affected the types of changes that SHAWCO may consider feasible. SHAWCO has operated historically in a highly politicised arena. During apartheid years SHAWCO was a massive presence in the community and was seen as a "benefactor" in the absence of effective official social services agencies. This role as a dispenser of aid appeared to be frozen in a time of struggle. At the time when this research was undertaken there was strong resistance from communities to SHAWCO developing and evolving into an organisation which focussed on its strengths. The student spent time observing and researching all aspects of SHAWCO's operations which meant he was able to pick up many of these aspects which shaped the way the organisation responded to the need for change. The final workshop was ultimately a means of presenting the knowledge gathered by the student during his preparation for the workshop, as well as the contrasting views of different members of SHAWCO, all of which put the organisation in a stronger, better informed position for making strategic decisions about the future.

As a small organisation reliant on volunteers, SHAWCO had not previously had the resources to engage in the luxury of a group visioning exercise and this research represented an opportunity for them to take this step (an example of a positive and synergistic interaction between two organisations engaged in Action Research such as mentioned in the introductory section). Nevertheless, problem structuring is demanding of an organisation in terms of time and focussed commitment, and the student had to battle the fact that there was an initial sense that the organisation could not afford to invest time in what appeared at first to be an academic exercise. The feedback after the process was that this research was instrumental in SHAWCO embarking on a process of structural change.

\subsection{The use of data mining as a decision making tool for municipal performance management in the Western Cape}

At the time of this dissertation (Rasmussen 2009) the Department of Local Government and Housing (DLGH) in the Western Cape had the responsibility for oversight of the functioning of municipalities in the province. It thus fell on them to assess the performance of these local government authorities with a clear focus on improving service delivery. Municipal performance is clearly a multi-dimensional outcome and the Department (as well as the municipalities) routinely collected data measuring efficacy in different aspects of performance e.g. financial management, service provision and governance. Clearly some of these dimensions are easier to measure quantitatively than others so information across the dimensions was uneven, as was quality of information across the municipalities which varied from non-existent, to patchy and erroneous, to fairly good.

Data mining tools are routinely used in the corporate environment to capitalise on high volumes of data. The Minister of DLGH had a similar need to the chief executive officer of a large corporate to be able to use the volumes of available data to provide timeous information so as to adjust policy and deliver support to municipalities. Multivariate statistical techniques such as cluster analysis, discriminant analysis and classification trees were used in this dissertation to attempt to cluster local municipalities and analyse their differences 
in order to define profiles of functioning, at risk and non-functioning municipalities. The student used an innovative approach in conducting a workshop to capture the views of officials from the DLGH, resulting in them clustering the municipalities into groups based on the officials' own expert opinions. A comparison of the expert opinion clusters with those generated via data mining formed the basis of a discussion around how to profile municipalities and which variables were able to effectively cluster municipal performance.

The data used in this analysis was of poor quality as there was a significant amount of missing data, incorrectly completed data and cases where data was not available at all. The student also invested time in presenting the results of the data mining in ways which were most likely to convey maximum information, in order to facilitate the oversight role of the DLGH. Through interaction with members of the department, it was found that cluster analysis was thought to be the most useful data mining technique because it was the easiest method to understand and relationships present in the data could be easily presented in a visual manner.

\subsection{Providing strategic and operational support to Foodbank South Africa}

Two students conducted dissertations on various strategic and operational issues arising during the establishment of a food banking operation in Cape Town (Blake 2010; Watson 2011). A food bank is a facility that redistributes surplus food from large retailers/suppliers to agencies (organizations with feeding programs). The work conducted by the first student directly helped with the planning, creation and launch of the first food bank facility in Cape Town (FBCT). The second dissertation addressed the operational issue of how best to allocate available food to agencies.

Together the dissertations dealt with three main issues: the creation of a cohesive organizational structure for the smooth running of the food bank; the selection of a warehouse of a suitable size and location; and the development of an allocation model to assist with deciding which agencies to give food (and how much) for onward distribution to the needy.

For all three issues, the associated problems that needed to be solved in order to address the main issue were either ill-defined, messy or at best little understood. Furthermore, the issues lacked data, did not fit any of the traditional OR methods or could not benefit from the Global Foodbanking Network (GFN) expertise and experience in establishing and running foodbanking operations due to circumstances and socio-economic problems unique to South Africa. Due to the ill-defined nature of the problems, the students employed a combination of stakeholder workshops and a number of mainly soft OR methodologies to deal with them. The OR methodologies used included: soft systems methodology (Checkland 2000), strategic options development and analysis (Eden \& Ackermann 2001), system dynamics (Van den Belt 2004), multi-criteria decision making (Belton \& Stewart 2002) and simulation. Whilst no one method was implemented in full in resolving a specific problem, elements of each methodology that were seen as being beneficial were used. The ways in which each of the three main dissertation objectives were addressed is discussed in the following paragraphs.

Creating a coherent organizational structure: The team that was given the responsibility 
to establish FBCT was known as the Cape Town forum and was made up of a wide range of stakeholders as a result of early work done by GFN. The forum was extremely diverse, with representatives from the GFN, existing food agencies, major retailers, and agencies, but lacked structure, direction and clear leadership. Whilst individuals were committed and willing to work towards establishing a foodbank in Cape Town, there was no clarity on roles and responsibilities. An urgent intervention was required in order to bring all stakeholders on board and provide structure for the forum with clear indication of hierarchy, roles and responsibilities.

The use of problem structuring methods is important for a variety of reasons. These include the fact that client organisations - whether they be NGOs working in development contexts or for-profit organisations operating in the market - often operate under considerable pressures (financial, logistical, political, etc.) that may make them react in unpredictable ways. Individuals under pressure frequently develop a set of heuristic coping mechanisms which become entrenched (even when the pressures cease) and which are frequently not communicated to other team members. Developing a set of root definitions allowed stakeholders in this project to not only inform the researcher about their roles, functions and objectives, but also helped to communicate subtle differences of perspective to each other. It was clear that a solid problem structuring stage gave the client organisation confidence about the researcher and gave the researcher insight which led to the creation of solutions (tools) which were potentially useful.

Selecting a suitable warehouse location: The problem of selecting a warehouse came down to choosing among three options: to lease an existing warehouse; buy an existing warehouse; or find a plot of land and build one. Through forum meetings and input from experts in warehousing a number of criteria (including financial cost, office space, safety and security, size, location, facility condition, etc.) were determined for deciding which warehouse alternative would be most suitable. Following this exercise a number of warehouses were evaluated and a decision was made to lease a $1200 \mathrm{~m}^{2}$ warehouse at the Philippi Fresh Produce Market.

A specific challenge in evaluating potential solutions was that, because of the newness of the operation, there was considerable uncertainty about what size warehouse would be required. Traditionally, this decision is based on a thorough understanding of stock rotation and inventory management. The foodbank problem differs sharply from the typical classical inventory management problem in that it is supply (rather than demand) that is considered stochastic, while in South Africa demand is effectively deterministic - it will always exceed supply (this is not the case in the US, for example, where food suppliers are larger). Thus whilst for classical inventory management the decisions relate to when and how much to order, the decision variables for the foodbank relate to how much food to give out and when. Finally, while finance in food banking is a definite constraint, there is a different dynamic associated with cost, as food is generally donated, and the overall objective of the operation is to achieve positive social outcomes such as food security, rather than to unambiguously maximise profit. As a result of these differences in problem structure, many of the typical OR techniques for inventory management were not considered appropriate.

Supporting decisions about the allocation of food: At the time of the second dissertation, 
all allocation was done entirely manually. Donated food delivered daily to the Philippi warehouse was sorted and packed into crates of various categories before two floor managers manually determined how many and what type of food crates to give to each agency scheduled to receive food on that day. Their decisions were largely based on the number of people supported by each agency.

It quickly became apparent that any allocation system would depend heavily on the organisation's key goals and objectives, and that these had not been explicitly and fully stated. The dissertation thus used problem structuring methods to develop an understanding of the organisation's goals and how an allocation system could support these goals. This helped the researcher to gain an understanding of the way in which this NGO operated and gave a sense of what sort of tools or interventions would be useful and likely to be sustainable.

Following the problem structuring, a new allocation objective was proposed: maximising the minimum per-person nutritional content delivered to each agency on each day. A spreadsheet-based decision support tool was developed to implement the required optimisation and to provide support about decisions regarding the daily quantities of available food to allocate to agencies. A simulation model was used to compare the allocation rule to one which divides the available food in proportion to the number of people supported by each agency (i.e. the status quo). Results indicated that under the new allocation rule the minimum per-person nutritional content provided (across agencies) would increase by $80 \%$.

The simulation model was guided by available historical data regarding supply quantities and nutritional content. During the process of building the simulation it became clear that the available data was in fact of quite poor quality, which lead, during the course of the dissertation, to a new system of data capture. This highlights a common feature of working on a practical OR problem, whether in a developmental context or not - researchers often begin working on one problem and only find out on the way that further problems prevent the solution of the first issue. This, of course, again highlights the importance of the problem structuring phase. A related issue is that organisations under pressure are easily swept off course and a researcher has to be sensitive to (but not swamped by) the fact that, at times, issues of short term survival cloud the ability of the organisation to focus on long term improvements.

\section{Reflections on the ORD program at UCT}

It is clearly desirable to produce students with a strong repertoire of OR methods and tools that can be applied to the challenging suite of developmental problems facing us in South Africa. These challenges are such that excellent technical skills are necessary but not sufficient.

The ability to lead a participative, context-aware, inclusive approach that establishes solid foundations for work through rigorous problem structuring is a critical skill for the aspirant OR practitioner in South Africa. Moreover, it is an ability that is likely to benefit both developmental and more traditional OR problems (Ackoff, 1987). What emerges from the 
case studies is that good ORD practice is good OR practice.

For this reason the ORD program emphasises tools such as problem structuring, project management and system dynamics. A participative approach is at the heart of these tools (Checkland, 1998; Eden and Ackermann 2001), so that they tend to convey the essence of the participative approach to students in a more direct, accessible way than more traditional OR tools such as linear programming and mathematical modelling. These methods of course can, should, and often are applied in the same context-aware, inclusive manner, although this sometimes gets underemphasised when attempting to master material of a more technical nature. In the final analysis, students should be capable of applying whatever tool they use in a participative, context-aware, inclusive approach, and creatively adapt tools and methods to be both suitable and sustainable for long term solutions. The ability to work in this manner is a skill which takes maturity and experience to develop.

Sadly, attracting a sufficient number of students to meet minimum faculty requirements for running a taught Masters program has proved a major challenge for the ORD program, and following three cohorts of students enrolled between 2006 and 2010, the program was suspended. A total of nine students enrolled in the program, with seven ultimately graduating. We hope that the reader does not feel misled by our only revealing this detail now. Our intention is simply to convey some of our own disappointment and to highlight the distinction between good OR practice (which we believe the student dissertations were representative of) and the marketing of this practice (which would presumably help to draw a steady flow of students). It was generally acknowledged that a program of this nature requires aggressive marketing to launch, an activity which was not specifically provided for by the University and which proved onerous for individual staff members on top of normal academic duties and commitments. The primary problem is perhaps that OR and ORD are interdisciplinary in nature, and potential applicants may be drawn from a variety of fields. While this is also an opportunity, it makes targeted marketing of the program difficult, a challenge which is exacerbated by limited time and budget resources. The fact that there is no dedicated honours degree in OR at UCT, and thus no welldefined pool of applicants from which to draw, may also have contributed to the problem. A possible way forward would perhaps have been to combine forces within the department (to share courses across Masters programs of different quantitative hues) and also with other departments in the university that might have had similar niche interests. In the final analysis though, teaching and administering a program require quite different skills from advertising and marketing it, and unfortunately when resources are limited it may be the success of the latter which ultimately decides whether a program such as the MSc in ORD is sustainable. We offer these as suggestions for other academic institutions who may wish to set up a program of a similar nature. In the meantime, ideas for resurrecting the ORD program at UCT are still being explored, and it is hoped that its core concept and value may still take hold and grow.

\section{Conclusions}

In this paper we have provided a critical evaluation of a postgraduate program in operational research in development at the University of Cape Town. We used this assessment 
to explore issues around the training of a new generation of operational researchers possessing the skills required in contemporary South Africa i.e. in a developing country in which many pressing problems are of a development nature.

Debates on the role of OR in South Africa, either in education or in practice, cannot be entered without considering issues around development. We gave a brief summary of some of these highly contested issues while noting that, from the perspective of OR, much insight can be gained from practically-oriented documents like the Millennium Development Goals. We then reviewed the intersection between OR and development. Perhaps the most consistent message emerging from the literature is that development contexts are often characterised by a lack of various resources (e.g. money, data, technology and skills).

The MSc program in ORD, run at the University of Cape Town from 2006 to 2010, is described and a number of practical OR problems reviewed with a strong development focus addressed by students as part of their dissertations. The dissertations covered topics in sustainable livelihoods (spaza shop operations); health (antimalarial drug resistance); governance (NGO management structures and monitoring of local government performance) and poverty (food banking). Our main message is that, in addition to technical skills, the ability to lead a participative, context-aware, inclusive approach is a critical skill for the aspirant OR practitioner in South Africa. Accordingly, it is imperative that OR programs in South Africa teach these skills to students, particularly at the postgraduate level where closer contact with students is possible.

We ended the paper by briefly discussing the challenges involved with setting up and attracting sufficient students to maintain a postgraduate program in ORD in South Africa. Chief among these is the marketing of a interdisciplinary subject to potential applicants spread thinly around a number of related fields. Possible solutions in the case of UCT involve either increasing the focus on marketing, requiring additional scarce resources in the form of personnel or money, or to formalise a collaborative partnership with these related fields.

\section{Acknowledgements}

The authors would like to thank Jean-Marie Sabwa, Alexander Anyogu, Erica Rasmussen, Timothy Blake, Sheetal Silal and Neil Watson, whose dissertations were highlighted in this paper.

\section{References}

[1] Ackoff RL, 1987, Presidents' symposium: OR, a post mortem, Operations Research, 35(3), pp. 471474.

[2] Aggarwal SC, 1994, Practical applications of OR in an underdeveloped nation, European Journal of Operational Research, 77(3), pp. 357-374.

[3] Anderson RM \& May RM, 1980, The population dynamics of microparasites and their invertebrate hosts, Philosophical Transactions of the Royal Society B, 291(1054), pp. 451-524. 
[4] Anyogu A, 2012, The use of problem structuring methods to explore the functioning and management of a selected NGO, MSc Thesis, University of Cape Town, Cape Town.

[5] Belton V \& Stewart TJ, 2002, Multiple criteria decision analysis: An integrated approach, Kluwer academic publishers, Boston (MA).

[6] Blake T, 2010, An application of problem structuring methods to foodbanking in South Africa, MSc Thesis, University of Cape Town, Cape Town.

[7] Chambers R, 1994, The origins and practice of participatory rural appraisal, World Development, 22(7), pp. 953-969.

[8] Checkland PB, 1998, Systems thinking: Systems practice, $2^{\text {nd }}$ edition, John Wiley \& Sons, New York (NY).

[9] Checkland PB, 2000, Soft systems methodology: A thirty year retrospective, Systems Research and Behavioral Science, 17(1), pp. 11-58.

[10] Eden C \& Ackermann F, 2001, SODA - The Principles, pp. 21-41 in Rosenhead J \& Mingers J (EDs.), Rational Analysis for a Problematic World Revisited, John Wiley \& Sons, New York (NY).

[11] FATti LP, 1988, Current practice of operational research/management science in South Africa, Omega, 16(3), pp. 181-187.

[12] Fildes R, Ranyard JC, 1997, Success and survival of operational research groups $-A$ review, The Journal of the Operational Research Society, 48(4), pp. 336-360.

[13] Haouari M, Sherali HD, Mansour FZ \& Aissaoui N, 2011, Exact approaches for integrated aircraft fleeting and routing at TunisAir, Computational Optimization and Applications 49(2), pp. 213239.

[14] Kelly GA, 1955, The psychology of personal constructs, Norton, New York (NY).

[15] Ligthelm A, 2002, Characteristics of spaza retailers: Evidence from a national survey, Bureau of Market Research, University of South Africa, Pretoria.

[16] Ligthelm A, 2005, Informal retailing through home-based micro-enterprises: The role of spaza shops, Development Southern Africa, 22(2), pp. 199-214.

[17] Neiva de Figueiredo J, 2012, A decision support methodology for increasing school efficiency in Bolivia's low-income communities, International Transactions in Operational Research, 19(1/2), pp. 99121.

[18] Perks S, 2010, Exploring the management abilities of spaza shop owners in the Nelson Mandela metropolitan municipality, South African Journal of Economic and Management Sciences, 13(4), pp. 447-463.

[19] RAND GK, 2004, Developing countries OR for developing countries: The role of IFORS, Direct Connection to Developing Countries, 12(2), pp. 3-5.

[20] RAPLey J, 1996, Understanding development: Theory and practice in the Third World, Lynne Rienner Publishers, London.

[21] Rasmussen E, 2009, The use of data mining as a decision making tool for municipal performance management in the Western Cape, MSc Thesis, University of Cape Town, Cape Town.

[22] Rosenhead J, 1993, Enabling analysis: Across the developmental divide, Systemic Practice and Action Research, 6(2), pp. 117-138.

[23] Rosenhead J \& Tripathy A, 1996, Operational Research for Development, New Age International, Delhi.

[24] Rossouw RF, Coetzer RLJ \& Pretorius PD, 2010, Simulation experiments for maximising the availability of a commercial octene production facility, ORiON, 26(1), pp. 53-77.

[25] Sabwa JM, 2009, An application of problem structuring methods to the spaza shop system in South Africa, MSc Thesis, University of Cape Town, Cape Town.

[26] Scavarda A, Bouzdine-Chameeva T, Goldstein S, Hays J \& Hill A, 2006, A methodology for constructing collective causal maps, Decision Sciences, 37(2), pp. 263-283. 
[27] SCOTT L, 2005, Unpacking developmental local government using soft systems methodology and MCDA tools, ORiON, 21(2), pp. 173-195.

[28] Sсотт L, 2005a, Participatory multi-criteria decision analysis: A new tool for integrated development planning, Development Southern Africa, 22(5), pp. 695-716.

[29] Silal SP, 2009, A simulation model of antimalarial drug resistance, MSc Thesis, University of Cape Town, Cape Town.

[30] Stewart TJ, 1995, OR practice in South Africa, European Journal of Operational Research, 87(3), pp. 464-468.

[31] Stewart TJ, 2006, Operational research for development in Africa, International Conference on Modelling, Simulation and Optimization (MSO2006), Gaborone. (Paper available from author on request.)

[32] VAN DEN BeLt M, 2004, Mediated modeling: A system dynamics approach to environmental consensus building, Washington (DC).

[33] Walsham G, 1978, Education in Operational Research for developing countries, Journal of the Operational Research Society 29(4), pp. 299-306.

[34] Watson NM, 2011, Developing decision support for Foodbank South Africa's allocation system, MSc Thesis, University of Cape Town, Cape Town.

[35] White L \& Lee GJ, 2009, Operational research and sustainable development: Tackling the social dimension, European Journal of Operational Research, 193(3), pp. 683-692.

[36] White L, Smith H \& Currie C, 2011, OR in developing countries: A review, European Journal of Operational Research, 208(1), pp. 1-11.

[37] Willis K, 2005, Theories and practices of development, Routledge, London.

[38] World Bank, 2012, Working for a world free of poverty, [Online], [Cited: $16^{\text {th }}$ April 2013], Available from: http://data. worldbank.org/about/country-classifications/country-and-lending-groups.

[39] YouseF DA, 2009, Current status of operations research/management science education at the United Arab Emirates business schools, Education, Business and Society: Contemporary Middle Eastern Issues, 2(3), pp. 191-202.

[40] Zachariah R, Ford N, Maher D, Bissell K, Van den Bergh R, van den Boogaard W, Reid T, Castro KG, Draguez B, von Schreeb J, Chakaya J, Atun R, Lienhardt C, Enarson DA \& HARRIES AD, 2012, Is operational research delivering the goods? The journey to success in low-income countries, Lancet Infectious Diseases, 12(5), pp. 415-421. 